\title{
СОГЛАСОВАННАЯ ДИНАМИКА СЫВОРОТОЧНОГО IGЕ И ЧИСЛЕННОСТИ IGE+-КЛОНОТИПОВ С УРОВНЕМ ПЫЛЬЦЫ В ВОЗДУХЕ ПРИ ПОЛЛИНОЗЕ
}

А. И. Микелов ${ }^{1,2}$, Д. Б. Староверов², Е. А. Комечеч,3, Ю. Б. Лебедев²,3, Д. М. Чудаков²,2,3, И. В. Звягин

Сколковский институт науки и технологий, Москва, Россия

2 Институт биоорганической химии имени М. М. Шемякина и Ю. А. Овчинникова, Москва, Россия

${ }^{3}$ Российский национальный исследовательский университет имени Н. И. Пирогова, Москва, Россия

Механизмы поддержания иммунологической памяти, обусловливающей хроническое течение сезонного аллергического ринита у человека, слабо изучены. Рациональный дизайн новых подходов к терапии аллергических заболеваний требует детального понимания этих механизмов. Известно, что уровень аллергенспецисичных антител класса $\mathrm{lgE}$ (slgE), являющихся ключевым агентом в развитии данного заболевания, повышен у пациентов с поллинозом в период цветения. Целью работы было изучить динамику сывороточного уровня IgE и характеристик клонального репертуара IgEсекретирующих лимфоцитов в зависимости от интенсивности контакта пациента с аллергеном. Для трех пациентов (22, 22 и 28 лет) с аллергией на березовую пыльцу были измерены уровни общего IgE и slgE к березовой пыльце в 6 временных точках с интервалом в 2 недели, влючая период пыления березы. Для одного донора получены данные о клональном репертуаре генов тяжелых цепей иммуноглобулинов (IGH) субпопуляций B-клеточного ряда. Прирост уровня slgE в период пыления составил 91\%, 37\% и 64\% по сравнению с исходным у трех доноров. Момент начала роста уровня slgE и общего IgЕ и его динамика согласуются с ростом концентрации аллергена (slgЕ: $R^{2}=0,98$ при $p<0,05 ; \lg$ общий: $R^{2}=0,95$ при $\left.p<0,05\right)$. lgЕ-клонотипы обнаружены только в образцах, взятых в период цветения березы, что свидетельствует о росте их концентрации в этот период. Доля IgEклонотипов оказалась крайне низкой по сравнению с клонотипами других изотипов (IgE — 0,01\%, IgM — 48,4\%, IgD — 14\%, IgG — 17,4\%, IgA — 19,8\%). Оценка числа гипермутаций и филогенетический анализ последовательностей внутри 13 обнаруженных IgE-содержащих клональных групп показали возможность происхождения IgE-клонотипов из $\lg \mathrm{G}$ в результате смены изотипа

Ключевые слова: аллергический риноконъюнктивит, аллергенспецифичный IgE, пыльца березы, сезонная динамика, клональный репертуар иммуноглобулинов

Финансирование: исследование выполнено при поддержке Совета по грантам Президента Российской Федерации (грант МК6000.2018.4).

Благодарности: выражаем большую признательность всем донорам, принявшим участие в исследовании.

Информация о вкладе авторов: А. И. Микелов - определение уровня антител, подготовка библиотек кДНК IGH, анализ данных секвенирования и полученных результатов, дизайн исследования, подготовка рукописи; Д. Б. Староверов - выделение клеточных субпопуляций с помощью проточной цитофлюорометрии; Е. А. Комеч - сбор образцов крови, выделение клеточных субпопуляций с помощью проточной цитослюорометрии; Ю. Б. Лебедев - анализ и обсуждение полученных результатов, консультативная поддержка; Д. М. Чудаков - анализ и обсуждение полученных результатов, консультативная поддержка подготовки библиотек кДНК; И. В. Звягин — подготовка библиотек кДНК IGH, анализ данных секвенирования и полученных результатов, дизайн исследования, подготовка рукописи, организация исследования.

Соблюдение этических стандартов: исследование проведено в полном соответствии с требованиями Хельсинской декларации 2013 г.; все доноры подписали добровольное информированное согласие на участие в исследовании. Забор образцов крови выполнен квалифицированным медицинским персоналом в сертисицированных кабинетах компании «ИНВИТРО».

$\varangle$ Для корреспонденции: Иван Владимирович Звягин

ул. Миклухо-Маклая, д. 16/10, г. Москва, 117997; izvyagin@gmail.com

Статья получена: 09.10.2019 Статья принята к печати: 23.10.2019 Опубликована онлайн: 31.10.2019

DOI: $10.24075 /$ vrgmu.2019.072

\section{CORRELATED DYNAMICS OF SERUM IGE AND IGE+ CLONOTYPE COUNT WITH ALLERGEN AIR LEVEL IN SEASONAL ALLERGIC RHINITIS}

Mikelov $\mathrm{Al}^{1,2}$, Staroverov $\mathrm{DB}^{2}$, Komech $\mathrm{EA}^{2,3}$, Lebedev $\mathrm{YB}^{2,3}$, Chudakov DM ${ }^{1,2,3}$, Zvyagin IV ${ }^{2,3} \otimes$

Skoltech, Moscow, Russia

2 Shemyakin-Ovchinnikov Institute of Bioorganic Chemistry, Moscow, Russia

${ }^{3}$ Pirogov Russian National Research Medical University, Moscow, Russia

Mechanisms of maintenance of immunological memory in the chronic course of seasonal allergic rhinitis remain poorly understood. The detailed understanding of these mechanisms is required for design of new approaches for allergy treatment. It is known that the level of allergen-specific IgE antibodies (slgE), which play a key role in the development of the disease, is increased in patients with seasonal allergic rhinitis during pollination season. This study aimed to investigate the dynamics of serum IgE levels and characteristics of the clonal repertoire of IgE-secreting lymphocytes depending on the intensity of the patient's contact with the allergen. For three patients, allergic to birch pollen $(22,22$, and 28 y.o.), we measured total lgE and birch pollen specific lgE levels at 6 time points with 2 week interval during the birch pollination season. Immunoglobulin heavy chain gene (IGH) clonal repertoire data for several B-cell subpopulations at different time points were obtained for one patient. We observe growth of the slgE level ( $91 \%$, 37\%, and $64 \%$ compared to the baseline) at the peak of pollination season in all three donors. Initial increase in slgE and total IgE levels coincides with the birch pollination initiation; slgE and total lgE levels correlate with the birch pollen air level (slgE: $R^{2}=0.98$ at $p<0.05$; total IgE: $R^{2}=0.95$ at $p<0.05$ ). We detected lgE clonotypes only in samples obtained during the birch pollination, which indicates an increase of IGE-expressing cells concentration during this period. The frequency of IgE clonotypes was extremely low compared to that of the clonotypes of other isotypes (IgE - 0.01\%, IgM - 48.4\%, IgD - 14\%, IgG - 17.4\%, IgA - 19.8\%). Hypermutation and phylogenetic analysis of the sequences from the 13 detected IgE-containing clonal groups showed that these lgE clonotypes could originate from IgG as a result of sequential isotype-switching.

Keywords: allergic rhinitis, allergen-specific IgE, birch pollen, seasonal dynamics, immunoglobulin clonal repertoire

Funding: the study was supported by the Grant Council of the President of the Russian Federation (grant MK6000.2018.4).

Acknowledgments: we are very grateful to all the donors who participated in the study.

Author contribution: Mikelov AI - ELISA, preparation of IGH cDNA libraries, sequencing data and results analysis, research design, drafting the manuscript; Staroverov DB - cell subpopulations isolation (flow cytometry); Komech EA — blood samples collection, cell subpopulations isolation (flow cytometry); Lebedev YB - results analysis and discussion, advisory support; Chudakov DM — results analysis and discussion, advisory support (cDNA libraries preparation); Zvyagin IV - preparation of IGH cDNA libraries, sequencing data and results analysis, research design, drafting the manuscript, research organization.

Compliance with ethical standards: the study was conducted in full compliance with the requirements of the 2013 Helsinki Declaration; all donors signed a voluntary informed consent to participate in the study. Blood samples were taken by qualified medical personnel in the certified clinic ("Invitro").

$\triangle$ Correspondence should be addressed: Ivan V. Zvyagin

Miklukho-Maklaya, 16/10, Moscow, 117997; izvyagin@gmail.com

Received: 09.10.2019 Accepted: 23.10.2019 Published online: 31.10.2019

DOI: 10.24075/brsmu.2019.072 
Сезонный аллергический риноконъюнктивит (САР), или поллиноз, - одно из наиболее распространенных аллергических заболеваний. В странах Европы его распространенность достигает, по разным оценкам, 17-28\% от популяции [1]. Значительная часть пациентов с поллинозом (8-16\% от всего населения) сенсибилизирована к пыльце деревьев, и наиболее распространенным аллергеном является пыльца березы [2]. САР, как и другие аллергические заболевания, у большинства больных имеет хроническое течение, с высокой вероятностью развития сопутствующих патологий, таких как астма и пищевая аллергия. При этом наиболее широко применяемые терапевтические средства направлены лишь на облегчение тяжести симптомов заболевания (антигистаминные и глюкокортикостероидные препараты, стабилизаторы мембран тучных клеток). Аллергенспецифичная иммунотерапия единственный современный подход к лечению САР направленный на долгосрочное изменение хронического течения заболевания. Она требует длительного курса лечения, тщательного соблюдения пациентами режима, и лишь у части пациентов приводит к полному исчезновению симптомов [3]. В силу этого, разработка новых терапевтических подходов, направленных на предотвращение хронического течения САР, является крайне актуальной задачей.

Рациональный дизайн таких подходов требует глубокого понимания механизмов поддержания иммунологической памяти, обусловливающей хроническое течение аллергии. Ряд недавних неудачных клинических испытаний методов терапии аллергического ринита демонстрируют недостаточность имеющихся сведений об этих механизмах $[4,5]$. Фундаментальные исследования, направленные на более глубокое изучение механизмов сохранения иммунологической памяти, обусловливающей хроническое течение аллергии, являются необходимым базисом как для разработки новых терапевтических подходов для лечения САР, так и для совершенствования существующих.

Известно, что одним из ключевых агентов в развитии аллергического ответа является аллергенспецифичный иммуноглобулин класса E (lgE). Однако клеточные субпопуляции, продуцирующие IgE при аллергическом рините, остаются слабо охарактеризованными - не ясны их локализация, длительность существования, необходимые факторы для их поддержания. С использованием мышиной модели пищевой аллергии недавно было показано, что вскоре после сенсибилизации IgE-секретирующие плазматические клетки могут быть обнаружены в костном мозге и имеют ограниченный период жизни (до года) [6]. Антитела класса IgE при этом могут сохраняться до 100 дней связанными на мембранах тучных клеток. Показано также, что, по крайней мере, часть долгосрочной иммунологической памяти, обусловливающей хроническое течение аллергии, обеспечена субпопуляцией $\operatorname{lgG} 1^{+}$ аллергенспецифических В-лимфоцитов памяти, служащей «резервуаром», из которого пополняется популяция lgEпродуцентов в случае контакта организма с аллергеном [6, 7].

Целью данной работы было более детальное, по сравнению с ранее проведенными исследованиями [8-10], изучение динамики сывороточного уровня IgE у пациентов с аллергией на березовую пыльцу в зависимости от интенсивности контакта пациента с аллергеном, обусловленной уровнем аллергена в воздухе. В рамках исследования мы стремились ответить на вопрос, в какой момент времени относительно контакта с аллергеном, может происходить пополнение IgЕ-секретирующей фракции клеток, и охарактеризовать представленность и связь с другими изотипами и субпопуляцией В-клеток памяти клонов IgЕ-секретирующих плазмобластов и плазматических клеток периферической крови пациентов на фоне сезонного обострения заболевания.

\section{ПАЦИЕНТЫ И МЕТОДЫ}

\section{Выборка пациентов и сбор образцов сыворотки}

Исследуемая группа включала трех пациентов (22, 22 и 28 лет). Критерии включения пациентов в исследование: 1) пациенты обоих полов; 2) наличие ранее клинически установленного диагноза "сезонный аллергический ринит на березовую пыльцу»; 3) отсутствие диагноза «бронхиальная астма»; 4) отсутствие других хронических воспалительных, аутоиммунных, онкологических и инфекционных заболеваний. Критерии исключения: 1) прохождение пациентом курса аллергенспецифической иммунотерапии до или в период проведения исследования; 2) прохождение вакцинации в период проведения исследования. Забор образцов венозной крови производили в медицинских лабораториях и медицинским персоналом сети КДЛ «ИНВИТРО» с использованием пробирок Vacuette Serum Gel Z и Vacuette K3EDTA (BD Biosciences; CША). Дальнейшую экспериментальную работу проводили в условиях научно-исследовательской лаборатории ИБХ РАН.

Сбор образцов сыворотки крови для измерения уровня общего IgE и уровня специфичных к пыльце березы и ольхи $\lg Е$ проводили, начиная с марта по май 2019 г. с интервалом в две недели (суммарно 6 образцов для каждого донора). Для одного из доноров (28 лет) были дополнительно собраны образцы сыворотки в марте и мае 2017, а также в марте и мае 2018 г.

\section{Иммуноферментный анализ}

Выделение сыворотки осуществляли в соответствии с протоколом производителя пробирок (BD Biosciences; США). Иммуноферментный анализ для определения уровня общего IgE и уровня специфичных к пыльце березы и ольхи IgE проводили при помощи коммерчески доступных наборов для ИФА (Алкор Био; Россия) согласно протоколу производителя. Измерение оптической плотности проводили с помощью планшетного ридера Hidex Sense (Hidex Oy; Финляндия). Для каждого образца сыворотки выполняли ИФА в двух независимых повторах.

\section{Выделение субпопуляций В-лимфоцитов памяти, плазмобластов и плазматических клеток}

Для одного из доноров (28 лет) в трех временных точках (март и май 2017, март 2018) были получены образцы трех клеточных субпопуляций В-клеточного происхождения В-лимфоцитов памяти, плазмобластов и плазматических клеток периферической крови.

Из образца цельной крови донора выделяли фракцию мононуклеарных клеток периферической крови с помощью центрифугирования в градиенте плотности фиколла на центрифуге Eppendorf 5804 при 310 g в течение 20 мин (Eppendorf; Германия). Далее клетки окрашивали при помощи набора флуоресцентно-меченых антител к мембранным маркерам человека: anti-CD19-APC, antiCD20-VioBlue, anti-CD27-VioBright FITC, anti-CD138-PEVio770 (Myltenyi Biotec; CШA), после чего при помощи 
фрлуоресцентно-активированного клеточного сортинга (BD FacsAria III, BD Biosciences; CША) были выделены целевые субпопуляции В-клеточного происхождения: В-лимсоцить памяти (CD19+ CD20+ CD27+), плазмобласты (CD20- CD19+ $\mathrm{CD}^{27^{++}}$CD138-) и плазматические клетки (CD20- CD19 Low/ $\left.\mathrm{CD}_{27}{ }^{+} \mathrm{CD} 138^{+}\right)$. Для каждой временной точки собирали по два образца В-лимфоцитов памяти (по 50000 клеток), плазмобластов и плазматических клеток (по 1000 и по 500 клеток соответственно).

\section{Секвенирование и анализ репертуаров В-клеточных рецепторов}

Подготовку библиотек кДНК тяжелых цепей иммуноглобулинов $(\mathrm{lgH})$ проводили в соответствии с опубликованным ранее протоколом [11], используя ряд модификаций. На этапе обратной транскрипции вводили адаптер с уникальным молекулярным идентификатором (UMI) и баркодом образца (табл. 1). Дальнейшую амплификацию проводили в два этапа с использованием праймеров, описанных в табл. 1. Секвенирование проводили на приборе Illumina Hiseq 2000/2500 (Illumina; США), парное чтение длиной $310+310$ нуклеотидов.

Разделение общего массива секвенирования по соответствующим образцам и сборку консенсусных последовательностей на основе уникальных молекулярных идентификаторов проводили при помощи программы MIGEC [12]. Аннотацию V-, D- , J- и C-сегментов, определение уникальных клональных последовательностей IGH (клонотипов) и оценку уровня гипермутаций проводили с использованием программы MIXCR [13]. Для сборки клональных последовательностей $\mathrm{IGH}$ использовали чтения, соответствующие последовательностям кДНК IGH, прочитанных как минимум дважды на основе результатов анализа последовательностей молекулярных баркодов. При этом в качестве клонотипа рассматривали нуклеотидную последовательность тяжелой цепи иммуноглобулинов, начиная от каркасного участка 1 (FR1) V-сегмента до конца J-сегмента, с учетом изотипа антитела, определяемого по 5'-фррагменту C-сегмента длиной 15-16 нуклеотидов. Анализ репертуаров, статистическую обработку результатов и регрессионный анализ проводили с использованием языка программирования R [14], иллюстрации подготовлены с использованием пакета ggplot2 [15]. Клональные группы определяли при помощи программы Change-O [16] по следующим критериям: в одну клональную группу входили все последовательности с одинаковой длиной CDR3 и V-сегментом IGH, и отличавшиеся не более чем на 15\% по нуклеотидной последовательности CDR3 IGH. Филогенетический анализ проводили с использованием программы MEGA 7 [17] (филогенетические деревья максимального правдоподобия, эволюционная модель GTR).

\section{Регрессионный анализ}

Для проверки гипотезы о наличии согласованной динамики сывороточного уровня slgЕ к березовой пыльце и уровня пыльцы березы в воздухе была разработана регрессионная

Таблица 1. Последовательности олигонуклеотидных праймеров, использованных при подготовке библиотек кДНК для секвенирования репертуаров IGH

\begin{tabular}{|c|c|c|}
\hline $\begin{array}{l}\text { Название } \\
\text { праймера }\end{array}$ & Назначение & Последовательность \\
\hline \multicolumn{3}{|c|}{ Синтез кДНК } \\
\hline SmartMK & $\begin{array}{l}\text { Адаптер для «смены матрицы» при синтезе кДНК. } \\
U=\mathrm{dU}, \mathrm{rG} \text {-riboG, } N \text { - нуклеотид из списка } \mathrm{A} / \mathrm{G} / \mathrm{C} / \mathrm{T}\end{array}$ & CAGUGGUAUCAACGCAGAGUACNNNNNNUTGAAAUNNNNNNUCTT(rG)4 \\
\hline hIGG_r1 & Изотип-специфичный праймер, IgG & GAAGTAGTCCTTGACCAGGCA \\
\hline hlGM_r1 & Изотип-специфичный праймер, IgM & GTGATGGAGTCGGGAAGGAAG \\
\hline hIGA_r1 & Изотип-специфичный праймер, IgA & GCGACGACCACGTTCCCATCT \\
\hline hIGD_r1 & Изотип-специфичный праймер, IgD & GGACCACAGGGCTGTTATC \\
\hline hIGE_r1 & Изотип-специфичный праймер, IgE & AGTCACGGAGGTGGCATTG \\
\hline \multicolumn{3}{|c|}{ ПЦР-амплификация, шаг 1} \\
\hline M1ss & Прямой праймер & AAGCAGTGGTATCAACGCA \\
\hline hIGG_r2 & Изотип-специфичный обратный праймер, IgG/lgE & CCAGGGGGAAGACCGATG \\
\hline hIGA_r2 & Изотип-специфичный обратный праймер, IgA & CTCAGCGGGAAGACCTTG \\
\hline hIGM_r2 & Изотип-специфичный обратный праймер, IgM & ACGAGGGGGAAAAGGGTTG \\
\hline hIGD_r2 & Изотип-специфичный обратный праймер, IgD & CCTGATATGATGGGGAACAC \\
\hline hIGE_r2 & Изотип-специфичный обратный праймер, IgE & GTCAAGGGGAAGACGGATG \\
\hline \multicolumn{3}{|c|}{ ПЦР-амплификация, шаг 2} \\
\hline M1s_long_i7 & Прямой праймер* & $\begin{array}{l}\text { CAAGCAGAAGACGGCATACGAGAT(i7)GTCTCGTGGGCTCGGAGATGTGTAT } \\
\text { AAGAGACAGTGGTATCAACGCAGAG }\end{array}$ \\
\hline hIGD_r2_long_i5 & Изотип-специфичный обратный праймер, $\lg \mathrm{D}^{*}$ & $\begin{array}{l}\text { AATGATACGGCGACCACCGAGATCTACAC(i5)TCGTCGGCAGCGTCAGATGT } \\
\text { GTATAAGAGACAGATATGATGGGGAACAC }\end{array}$ \\
\hline hIGM_r2_long_i5 & Изотип-специфичный обратный праймер, $\operatorname{lgM}^{*}$ & $\begin{array}{l}\text { AATGATACGGCGACCACCGAGATCTACAC(i5)TCGTCGGCAGCGTCAGATGT } \\
\text { GTATAAGAGACAGAGGGGGAAAAGGGTTG }\end{array}$ \\
\hline hIGA_r2_long_i5 & Изотип-специфичный обратный праймер, $\lg \mathrm{A}^{*}$ & $\begin{array}{l}\text { AATGATACGGCGACCACCGAGATCTACAC(i5)TCGTCGGCAGCGTCAGATGT } \\
\text { GTATAAGAGACAGCAGCGGGAAGACCTTG }\end{array}$ \\
\hline hIGGE_r2_long_i5 & Изотип-специфичный обратный праймер, $\operatorname{lgG} / \mathrm{lgE}^{*}$ & $\begin{array}{l}\text { AATGATACGGCGACCACCGAGATCTACAC(i5)TCGTCGGCAGCGTCAGATGT } \\
\text { GTATAAGAGACAGARGGGGAAGACSGATG }\end{array}$ \\
\hline
\end{tabular}

Примечание: * (i5) и (i7) - последовательности длиной 8 нуклеотидов, являющиеся образец-специфичными баркодами. 
модель. Исходные данные для построения модели представлены в табл. 2. Уравнение регрессии:

slgE_level $=b+k 1 \times$ pollen_level $+k 2 \times$ donorMRK $+k 3 \times$ donorLK,

где slgE_level - зависимая переменная, сывороточный уровень аллергенспецифичного IgE к аллергенам березовой пыльцы; pollen_level - переменная-предиктор, средний уровень пыльцы березы в воздухе (класс) в течение двух недель перед забором соответствующего образца крови для измерения сывороточного уровня lgE; donorMRK искусственная переменная-предиктор, принимающая значения 1 (донор MRK) и 0 (донор не MRK); donorLK искусственная переменная-предиктор, принимающая значения 1 (донор LK) и 0 (донор не LK); $b$ - свободный член уравнения регрессии, отражающий базальный уровень зависимой переменной, характерный для донора MS; $k 1, k 2, k 3-$ коэфффициенты уравнения регрессии (k1 отражает изменение зависимой переменной при изменении уровня пыльцы в воздухе на 1 класс пыления; k2 отражает разницу базального уровня специфичного IgE к березовой пыльце между донорами MRK и MS; k3 отражает разницу базального уровня специфичного IgE к березовой пыльце между донорами LK и MS.

Рассчитанные коэффициенты: $b=207,813$ ( $p<0,01$ ); $k 2=-194,4(p<0,01) ; k 1=6,474(p<0,05) ; k 3=-208,15$ ( $<<0,01)$. Скорректированный $R^{2}=0,98 ; p<0,01 ; F$-тест.

Аналогично разработана регрессионная модель для анализа согласованности динамики сывороточного уровня общего IgE с уровнем пыльцы березы в воздухе. В качестве зависимой переменной выбран сывороточный уровень общего lgE, в качестве переменных-предикторов те же переменные, что и для ранее описанной модели для slgE. Для данной модели (зависимая переменная - сывороточный уровень общего $\mathrm{lgE}$ получены следующие значения коэффициентов: $b=1299,05$ ( $p<0,01)$; $k 2=-1056,4(p<0,01) ; k 1=51,45(p<0,05) ; k 3=-1313,65$ (p < 0.01). Скорректированный $R^{2}=0,95 ; p<0,01 ; F$-тест.

\section{Данные пыльцевого мониторинга}

Данные пыльцевого мониторинга в г. Москве получены из открытых источников («Аллергофон»). Соответствие класса пыления количеству зерен пыльцы на кубический метр воздуха представлено в табл. 3.

\section{РЕЗУЛЬТАТЫ ИССЛЕДОВАНИЯ}

Повышение сывороточного уровня общего и специфичного к пыльце березы IgE происходит согласованно с повышением уровня пыльцы березы в воздухе

Сывороточный уровень общего и аллергенспецифичного к пыльце березы IgЕ был измерен в шести временных точках до и после начала сезона пыления березы. Абсолютные значения сывороточных уровней как специфичного (рис. 1А), так и общего IgE (рис. 1Б) значительно различаются между пациентами, при этом индивидуальные различия существенно превосходят различия между временными точками того же донора. У всех доноров наблюдается рост абсолютных значений slgE к пыльце березы и общего IgE от точки $1 \mathrm{k}$ точке 6. Уровень специфичного к аллергенам березы lgЕ коррелирует с уровнем общего IgЕ для каждого донора и превышает референсный уровень во всех временных точках (рис. 1).

Степень изменения уровня slgE к березовой пыльце и общего IgE на протяжении исследуемого периода

Таблица 2. Исходные данные, использованные для построения регрессионных моделей. Сывороточные уровни slgE к березовой пыльце и общего IgE, средний уровень пыльцы березы в воздухе

\begin{tabular}{|c|c|c|c|c|}
\hline $\begin{array}{l}\text { Временная } \\
\text { точка }\end{array}$ & Донор & $\begin{array}{l}\text { Сывороточный уровень slgE } \\
\text { к березовой пыльце, ME/мл }\end{array}$ & $\begin{array}{c}\text { Сывороточный уровень } \\
\text { общего IgE, ME/мл }\end{array}$ & $\begin{array}{c}\text { Средний уровень пыльцы березы } \\
\text { в воздухе, класс }\end{array}$ \\
\hline 1 & MS & 178,4 & 1066,3 & 0,00 \\
\hline 2 & MS & 192,4 & 1148,9 & 0,00 \\
\hline 3 & MS & 202,7 & 1275,9 & 0,07 \\
\hline 4 & MS & 232 & 1419,7 & 1,07 \\
\hline 5 & MS & 243,1 & 1469,4 & 3,83 \\
\hline 6 & MS & 244,3 & 1779,9 & 2,13 \\
\hline 1 & MRK & 15,7 & 273,7 & 0,00 \\
\hline 2 & MRK & 17,4 & 245,9 & 0,00 \\
\hline 3 & MRK & 17,6 & 288,5 & 0,07 \\
\hline 4 & MRK & 23 & 293,1 & 1,07 \\
\hline 5 & MRK & 27,1 & 358,3 & 3,83 \\
\hline 6 & MRK & 25,7 & 362,2 & 2,13 \\
\hline 1 & LK & 5,4 & 26,2 & 0,00 \\
\hline 2 & LK & 6,4 & 31,2 & 0,00 \\
\hline 3 & LK & 6,1 & 28,2 & 0,07 \\
\hline 4 & LK & 6,2 & 44,8 & 1,07 \\
\hline 5 & LK & 9,6 & 69,1 & 3,83 \\
\hline 6 & LK & 10,3 & 78,7 & 2,13 \\
\hline
\end{tabular}

Таблица 3. Уровень пыления - соответствие количества пыльцы в воздухе классам (уровням) пыления

\begin{tabular}{|c|c|c|c|c|c|}
\hline Количество зерен пыльцы на 1 м³ воздуха & 0 & $1-10$ & $11-100$ & $101-1000$ & $1001-5000$ \\
\hline Класс & 0 & 1 & 2 & 3 & 4 \\
\hline
\end{tabular}


существенно меньше различий в сывороточном уровне общего и специфичного IgE между донорами (коэффицциент вариации между всеми точками соответствующего донора для slgE к березе: MS - 0,130, MRK - 0,228, LK - 0,282; для IgE общего: MS - 0,189, MRK - 0,154, LK - 0,485); наименьший коэффициент вариации между донорами для slgE - 1,39; для общего $\lg Е-1,17)$. В связи с этим, для исследования значений в динамике уровни slgE к березовой пыльце и общего IgE в каждой последующей временной точке были рассмотрены относительно базовых уровней slgЕ и общего lgЕ для этого донора, т. е. до начала пыления березы (точка 1). Каждое измерение общего lgE и slgE к пыльце березы было нормировано на соответствующие значения общего lgE и slgE к пыльце березы в первой временной точке для каждого донора.

В соответствии с ранее опубликованными данными по сезонной динамике сывороточного уровня IgE, специфичного к другим пыльцевым аллергенам [8-10], в нашем исследовании также можно наблюдать значительное увеличение уровня slgE к пыльце березы между временной точкой вне сезона (точка 1) и в пик сезона пыления (точка 6) березы. При этом обнаружена согласованная динамика сывороточного уровня slgE к березе и уровня березовой пыльцы в воздухе (рис. 2). Наибольший прирост в уровне slgE происходит в период пика пыления березы, между точками 3 и 5: для донора LK он составил 90,7\%, для MRK - 63,7\%, для MS - 36,9\%.

Для статистической проверки гипотезы о связанности уровня пыльцы березы в воздухе и сывороточного уровня аллергенспецифичного IgE $\mathrm{k}$ пыльце березы была построена линейная регрессионная модель. В соответствии с моделью высокая доля дисперсии зависимой переменной (уровень slgE) обусловлена выбранными предикторами (скорректированный $R^{2}=0,98$ ), т. е. уровнем пыльцы в воздухе и идентисиккатором донора, что позволяет учесть значительные различия в абсолютном уровне slgE между донорами. При этом все коэффициенты статистически достоверно не равны 0 ( $<<0,05$ для всех коэффициентов), и коэффициент при переменной-предикторе, отражающей уровень пыльцы березы, больше $0(k 1=6,47)$, что служит статистическим подтверждением согласованности изменения уровня slgE в сыворотке с изменением уровня пыльцы березы в воздухе. Аналогично, регрессионная модель для уровня общего

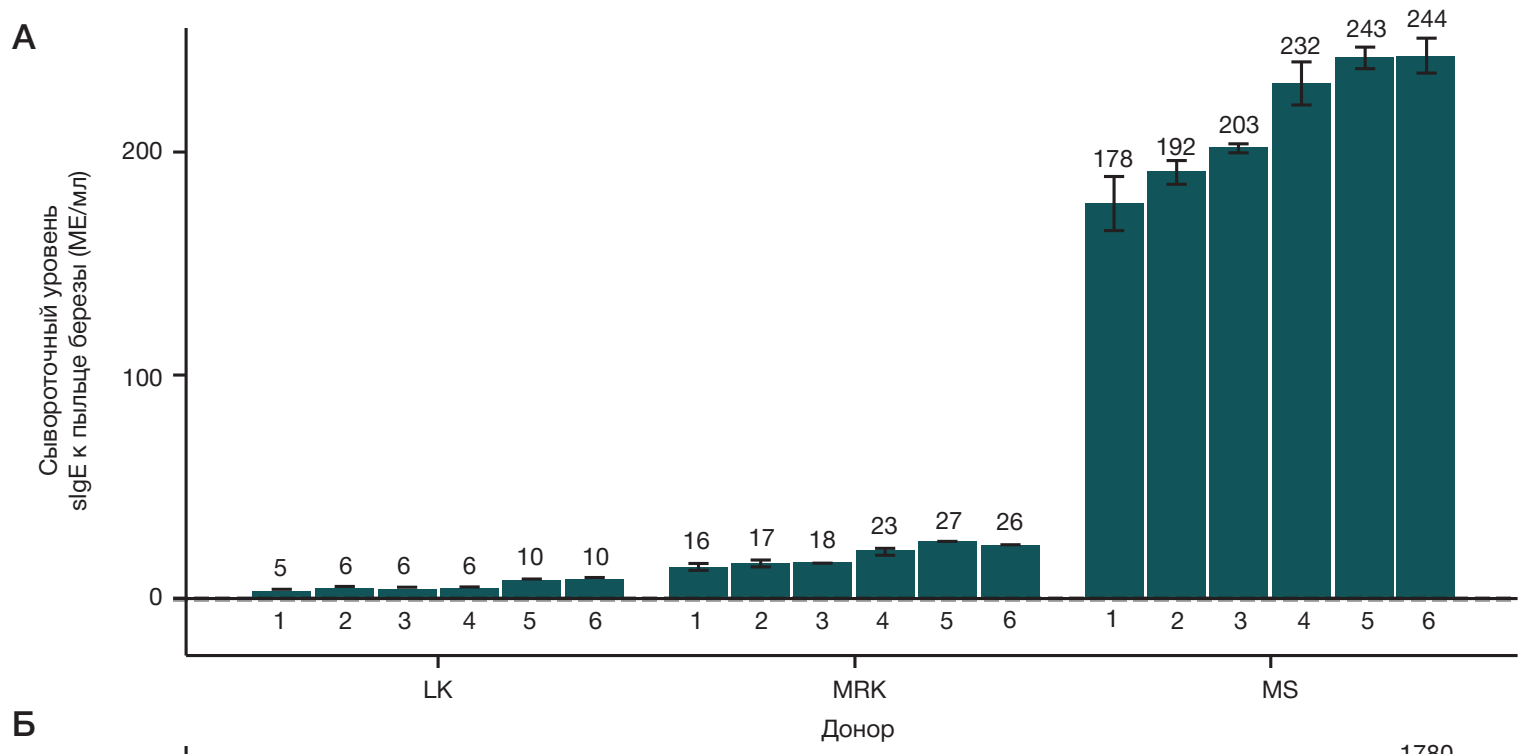

Б

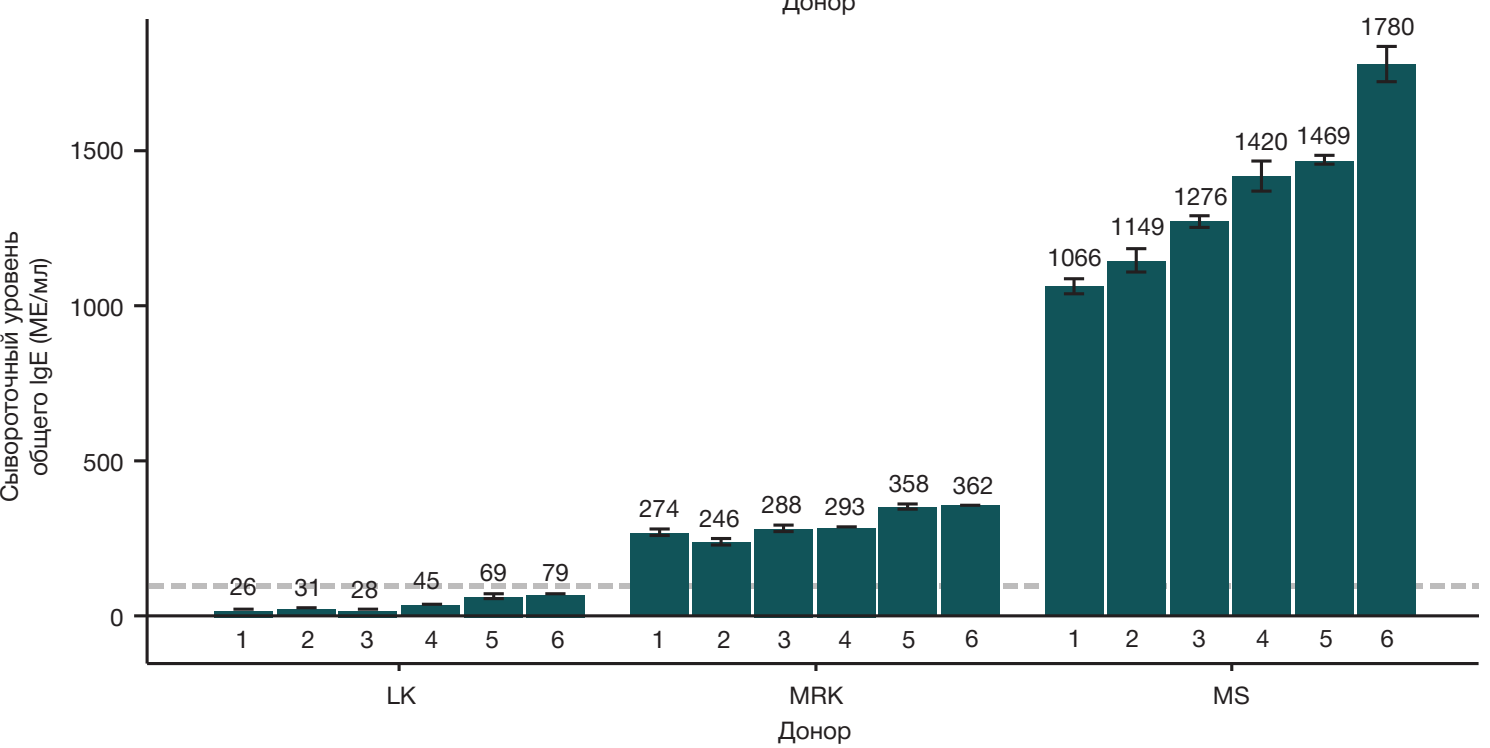

Рис. 1. Уровень специфичного IgE к пыльце березы (А) и общего IgE (Б) для трех доноров с сезонным аллергическим риноконъюнктивитом (LK, MRK, MS) в шести временных точках (1-6). Горизонтальная пунктирная линия отражает ресеренсный уровень соответствующих антител в сыворотке здорового взрослого донора (< 0,35 ME/мл - для slgE, <100 ME/мл - для общего IgE). Планки погрешностей отражают размах (разницу между минимальным и максимальным значениями измерения) 
IgE также демонстрирует согласованность повышения уровня общего $\mathrm{lgE}$ с концентрацией аллергена в воздухе (скорректированный $R^{2}=0,95 ; p<0,05$ для каждого из коэффициентов).

Стоит отметить, что относительно небольшое, по сравнению с максимально достигнутым за весь период наблюдения, повышение уровня slgE к пыльце березы происходит в промежутке до начала или при невысокой концентрации пыльцы березы (точки 1-3). Это можно объяснить случайными колебаниями уровня slgE к пыльце березы (для двух из трех доноров повышение абсолютного уровня между точками 1-2 и 2-3 не превышает $1 \mathrm{ME} / \mathrm{M} л)$ или более ранним контактом пациента с пыльцой березы, до того как повышение уровня пыльцы в воздухе было зарегистрировано станциями пыльцевого мониторинга. Такое повышение slgE к березовой пыльце может быть обусловлено также кросс-реактивностью slgЕ к пыльце березы в отношении антигенов из пыльцы ольхи из-за высокой степени гомологии антигенов [2] и предшествования пыления ольхи сезону цветения березы. Для оценки вклада кросс-реактивных IgE мы провели измерение уровня slgE к пыльце ольхи для всех собранных образцов сыворотки (рис. 3). У всех исследованных доноров уровень slgE к пыльце ольхи оказался в большей степени согласован с изменением уровня пыльцы березы в воздухе, чем пыльцы ольхи. Наибольший прирост уровня slgE к пыльце ольхи наблюдали между точками 4 и 5 в момент наибольшего прироста уровня пыльцы березы в воздухе, но не в момент наибольшего прироста уровня пыльцы ольхи в воздухе между точками 1 и 2. На основе этого можно предположить высокую степень кроссреактивности slgE к березовой пыльце в отношении антигенов пыльцы ольхи у всех исследованных доноров.

Между точками 1 и 2 для двух доноров (MRK, LK) небольшой рост уровня slgE к березовой пыльце (< 1 ME/Mл) сопровождало снижение уровня slgЕ к пыльце ольхи. Таким образом, показанное для доноров MRK и LK незначительное повышение уровня slgЕ к березовой пыльце не может быть объяснено кросс-реактивностью slgЕ к пыльце ольхи. У донора MS наблюдали рост slgE к ольхе между точками 1 и 2, что может объяснять повышение уровня slgE к березовой пыльце до начала сезона пыления березы.

\section{Представленность IgE-экспрессирующих клеток в субпопуляциях В-клеточного происхождения в периферической крови сравнительно низка и возрастает на фоне сезонного обострения аллергии}

Основываясь на данных, полученных с использованием мышиной модели пищевой аллергии, можно предположить,

A

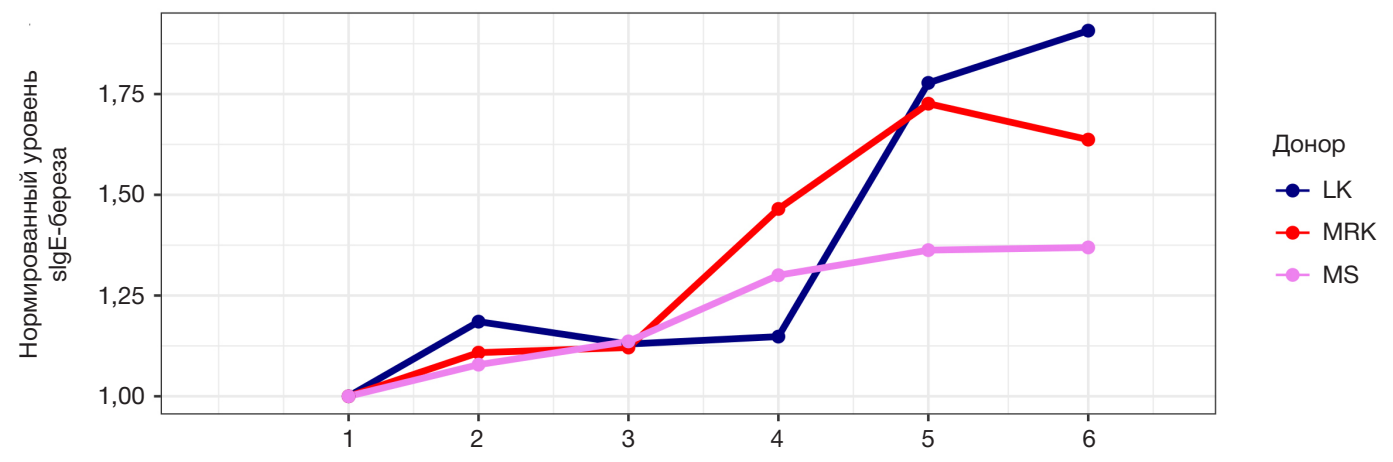

Б

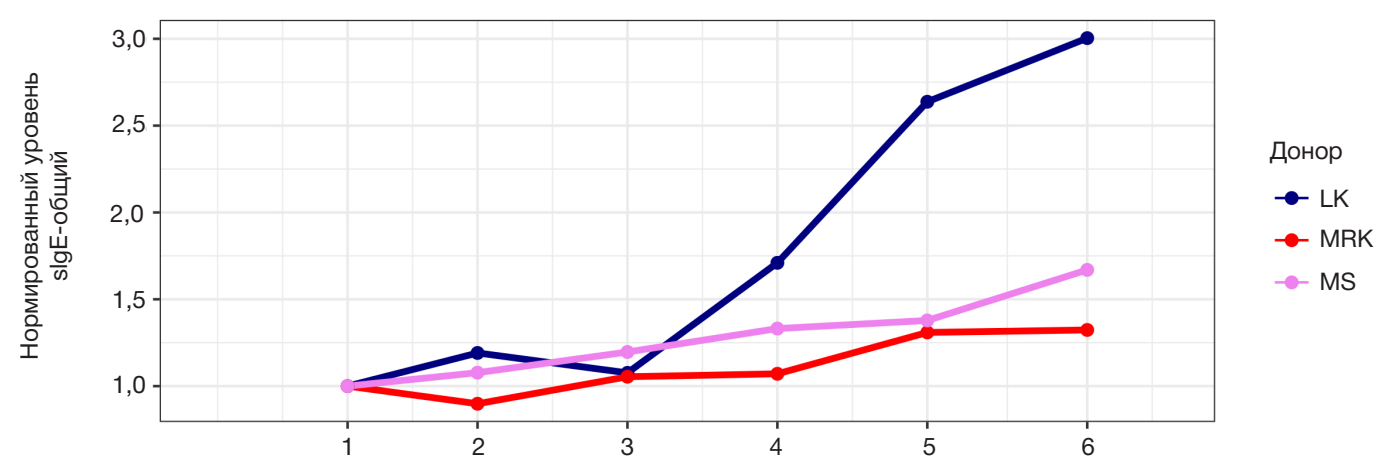

B

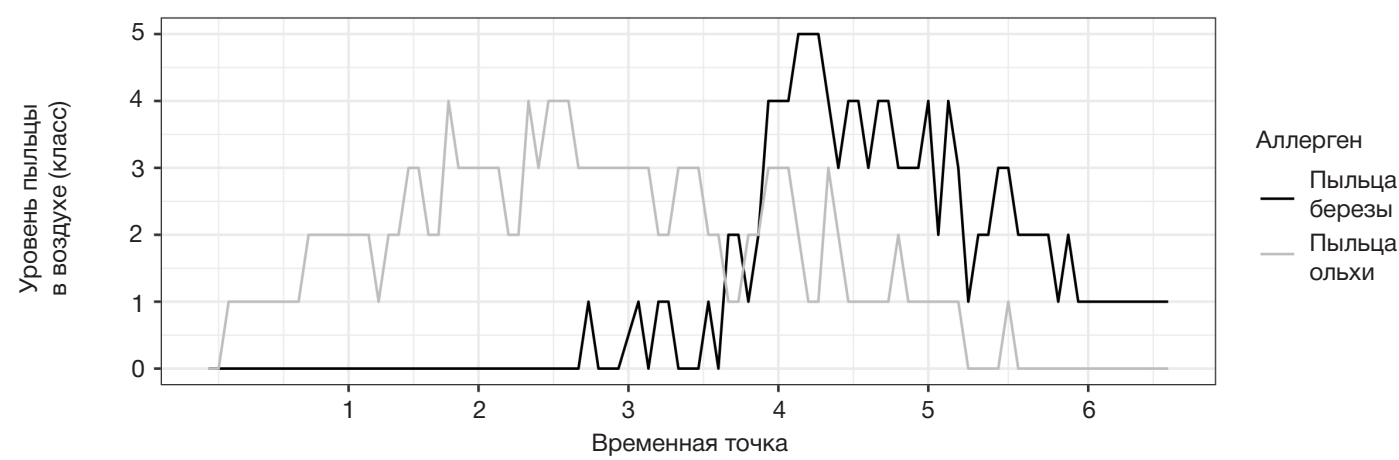

Рис. 2. Динамика уровня сывороточного IgE и уровня пыльцы березы в воздухе. А. Сывороточный уровень slgЕ к березовой пыльце в каждой временной точке, нормированный на уровень slgЕ к березовой пыльце в точке 1 для этого донора. Б. Сывороточный уровень IgЕ-общий в каждой временной точке, нормированный на уровень lgE-общий в точке 1 для соответствующего донора. В. Уровень пыльцы березы в воздухе 
что увеличение сывороточного уровня slgE к пыльце березы и общего IgE связано с увеличением числа IgEпродуцирующих клеток в организме. Чтобы оценить сезонную динамику представленности $\mathrm{lg}^{+}-$-клеток в субпопуляциях В-клеточного ряда (В-лимфоцитов памяти, плазмобластов, плазматических клеток), для одного из доноров было проведено исследование клональных репертуаров тяжелых цепей иммуноглобулинов (IGH) клеток периферической крови в трех временных точках («1_2017», «3_2018» - точки вне сезона пыления березы, «2_2017» - на пике сезона).

В результате секвенирования суммарно для всех трех временных точек было получено 50550291 прочтений, представляющих 1616747 уникальных молекулярных событий (молекул кДНК IGH, вошедших в анализ). Для дальнейшего анализа с целью исключения большинства ошибок в определении клональной последовательности использовали молекулярные события, для которых получено два или более прочтений. Всего было определено 116437 клонотипов IGH (клонотип определяют как уникальную нуклеотидную последовательность IGH от каркасного региона (FR1) V-сегмента до конца J-сегмента с учетом изотипа антитела). Среди обнаруженных IgE клонотипы представляли исключительно малую долю $(\sim 0,01 \%)$. Для сравнения: доля IgM клонотипов составила $48,4 \%, \lg D-14 \%$, IgG - 17,4\%, IgA - 19,8\%.

Bce IGE+-клонотипы были обнаружены в репертуарах тяжелых цепей иммуноглобулинов В-лимфоцитов памяти, плазмобластов и долгоживущих плазматических клеток исключительно в образцах, полученных в период сезона пыления березы (рис. 4). При этом число клеток в образце каждой субпопуляции не различается между временными точками. Полученный результат свидетельствует о повышении представленности IGE+-клеток в периферической крови пациента в сезон цветения березы.
Преимущество использованной технологии подготовки библиотек кДНК тяжелых цепей иммуноглобулинов в возможности оценки числа гипермутаций по всей длине последовательности IGH, начиная с региона FR1 и заканчивая началом константного участка. Для каждого клонотипа было определено число гипермутаций в зависимости от изотипа данной IGH. Ожидаемо, что наименьший уровень гипермутаций был детектирован среди IgD- и IgM-последовательностей (медиана - 2,3 и 3,7 п.о. на 100 п.о. последовательности V-сегмента соответственно), и более высокий - среди IgG- и IgA-клонотипов (медиана - 6,8 и 7,1 п.о. на 100 п.о. последовательности V-сегмента соответственно) (рис. 5), экспрессирующихся в В-лимфоцитах, прошедших через процесс созревания в герминативных центрах. При этом среднее число гипермутаций IgE-клонотипов было не ниже (медиана - 7,4 п.о. на 100 п.о. последовательности V-сегмента), чем для lgG- и IgA-клонотипов. Факт сходного числа гипермутаций у IgE- и IgG-клонотипов может свидетельствовать о возможном происхождении lgEклонотипов антителосекретирующих субпопуляций клеток из lgG+ В-лимсоцитов памяти, однако не исключает возможности независимого переключения изотипов и дальнейшего гипермутагенеза $\mathrm{lgE}^{+}$и lgG ${ }^{+}$В-лимсоцитов.

Для более детального анализа взаимосвязи IgЕ-клонотипов в репертуарах тяжелых цепей иммуноглобулинов с клонотипами других изотипов мь применили ранее опубликованный подход для определения клональных групп, т. е. наборов клонотипов, наиболее вероятно произошедших от единого предшественника и имеющих схожую, но не обязательно идентичную нуклеотидную последовательность, кодирующую вариабельный фрагмент тяжелой цепи В-клеточного рецептора [16]. Всего было выявлено 13 lgЕ-содержащих клональных групп, включавших в общей сложности

A

Б
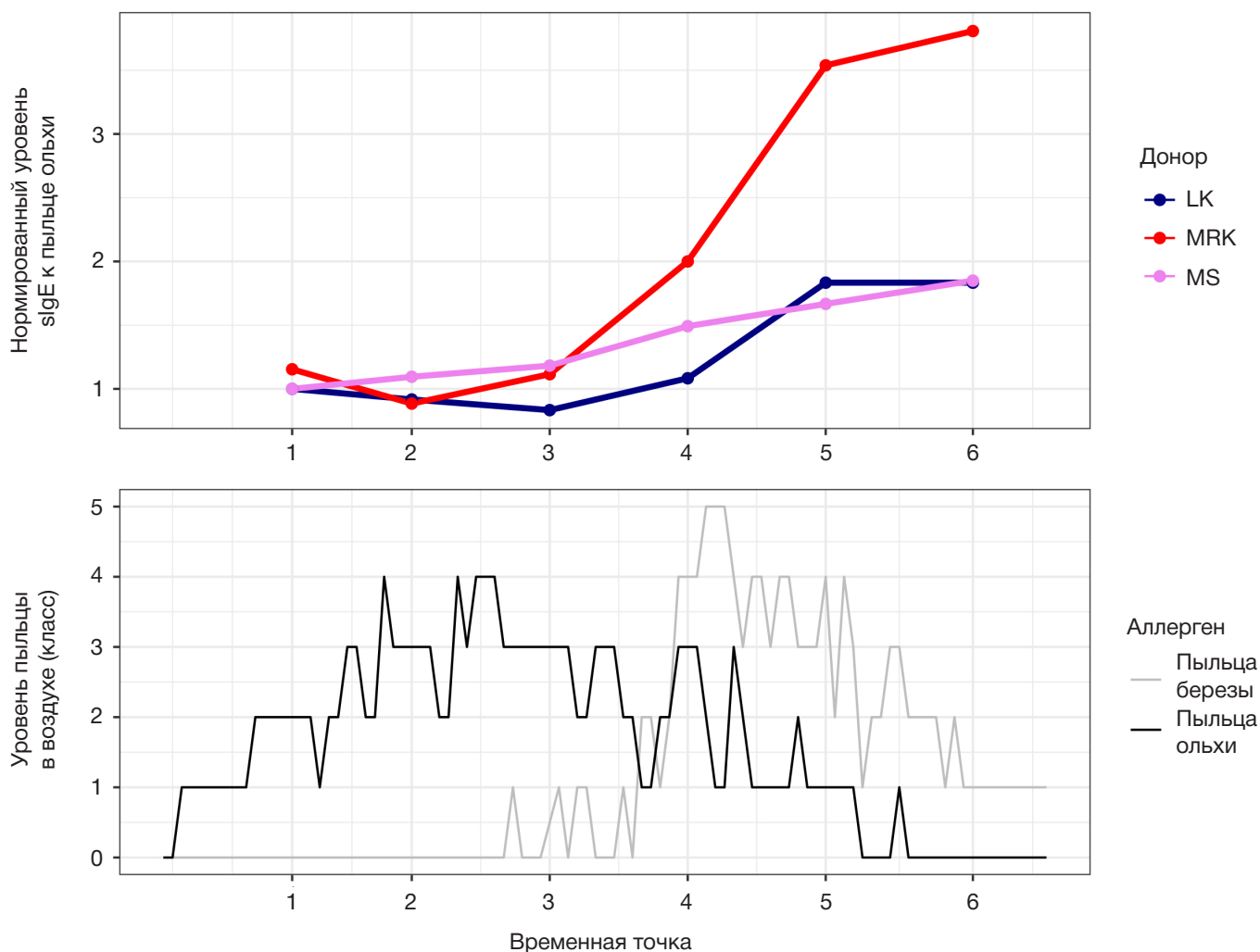

Рис. 3. Динамика уровня специфичного IgE к аллергенам пыльцы ольхи и уровня пыльцы в воздухе. А. Сывороточный уровень slgЕ к ольхе в каждой временной точке, нормирован на уровень slgE к березе в точке 1 для каждого донора. Б. Уровень пыльцы в воздухе 
154 клонотипа. В 4 из них были идентифицированы клонотипы других изотипов: IgG -82 , IgA - 19, IgM - 4 и $\operatorname{lgD}$ - 1. Филогенетический анализ, проведенный для клонотипов каждой из этих клональных групп, указывает на близкое родство IgE- и IgG-клонотипов (рис. 6) - для большинства IgE-клонотипов наиболее близким соседом по филогенетическому древу являлся IgG-клонотип. Стоит отметить, что в каждой из рассмотренных IgE-содержащих клональных групп присутствовали IgG-клонотипы, представлявшие фракцию lgG+ B-лимфоцитов памяти.

\section{ОБСУЖДЕНИЕ РЕЗУЛЬТАТОВ}

В ранее опубликованных исследованиях показан рост уровня сывороточного общего и аллергенспецифичного
IgE в период сезонного обострения аллергического ринита [8-10]. Вместе с тем в этих работах представлены данные о сезонной динамике сывороточного уровня антител собраны с периодичностью раз в несколько месяцев и вне связи с уровнем пыльцы, вызывающей аллергическую реакцию, в воздухе. В данной работе мы провели измерения сывороточного уровня общего lgE и специфичных IgE к пыльце березы и ольхи с большим разрешением по времени (периодичность анализа уровня антител - раз в две недели) в течение периода, захватывающего начало периода пыления. Сопоставление концентрации антител с количеством пыльцы в воздухе в каждой временной точке позволило продемонстрировать согласованную динамику уровня пыльцы березы в воздухе и сывороточного уровня slgЕ к березе и общего IgE. При

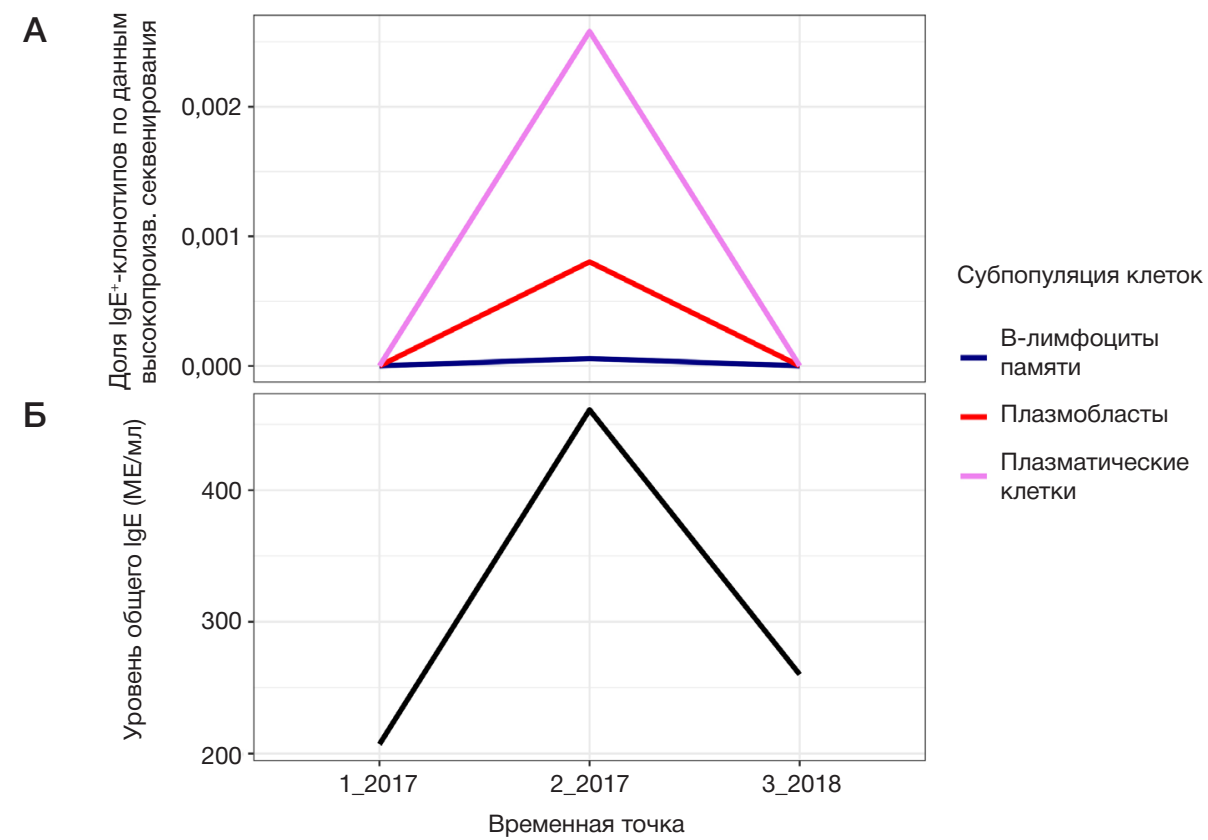

Рис. 4. Динамика клонального репертуара клеток В-ряда. А. Доля клонов с IgЕ-изотипом по результатам высокопроизводительного секвенирования репертуаров тяжелых цепей иммуноглобулинов для трех субпопуляций клеток периферической крови: В-лимфоцитов памяти, плазмобластов и плазматических клеток. Б. Уровень общего IgЕ в сыворотке донора в соответствующих временных точках

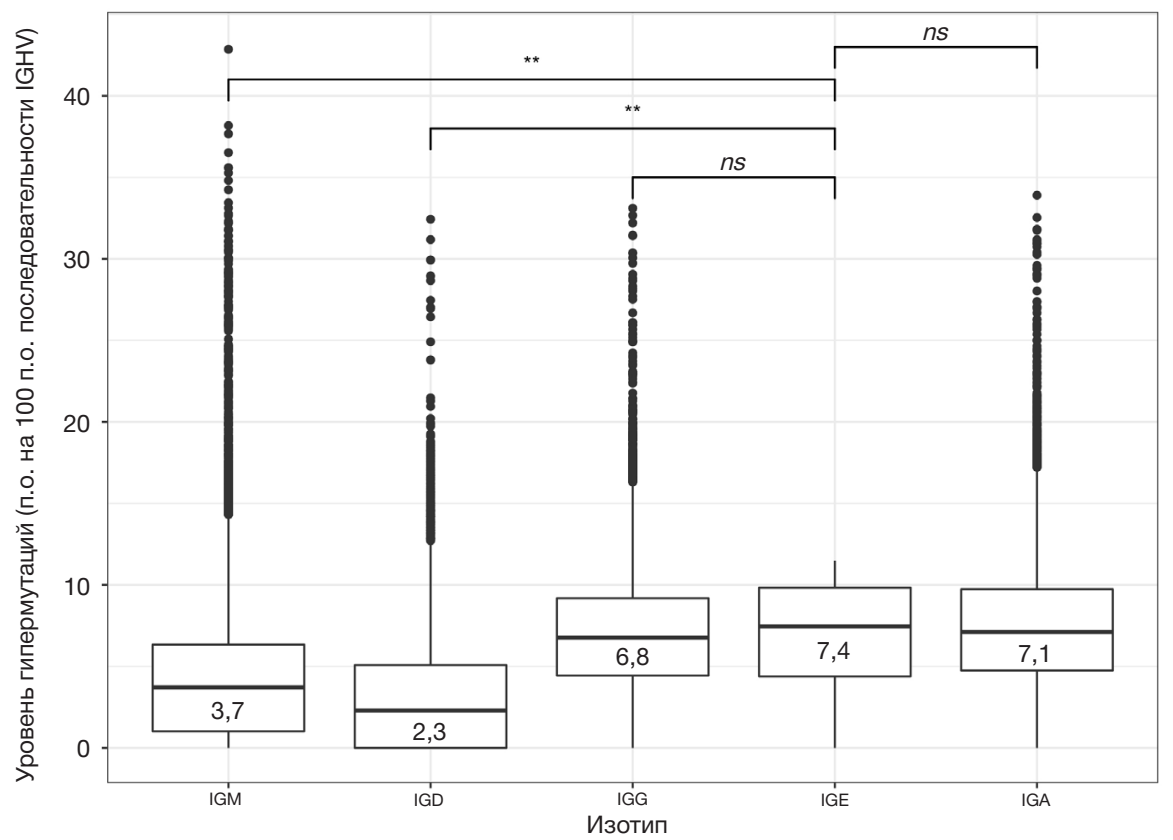

Рис. 5. Уровень гипермутаций (п.о. на 100 п.о. последовательности IGHV) по данным высокопроизводительного секвенирования репертуаров IGH. IGM $(n=55$ 865), IGD ( $n=15$ 834), IGG $(n=20$ 321), IGE $(n=13)$, IGA $(n=23$ 955). (** — $p<0,01 ; n s-$ незначимое различие; Т — критерий Уилкоксона) 


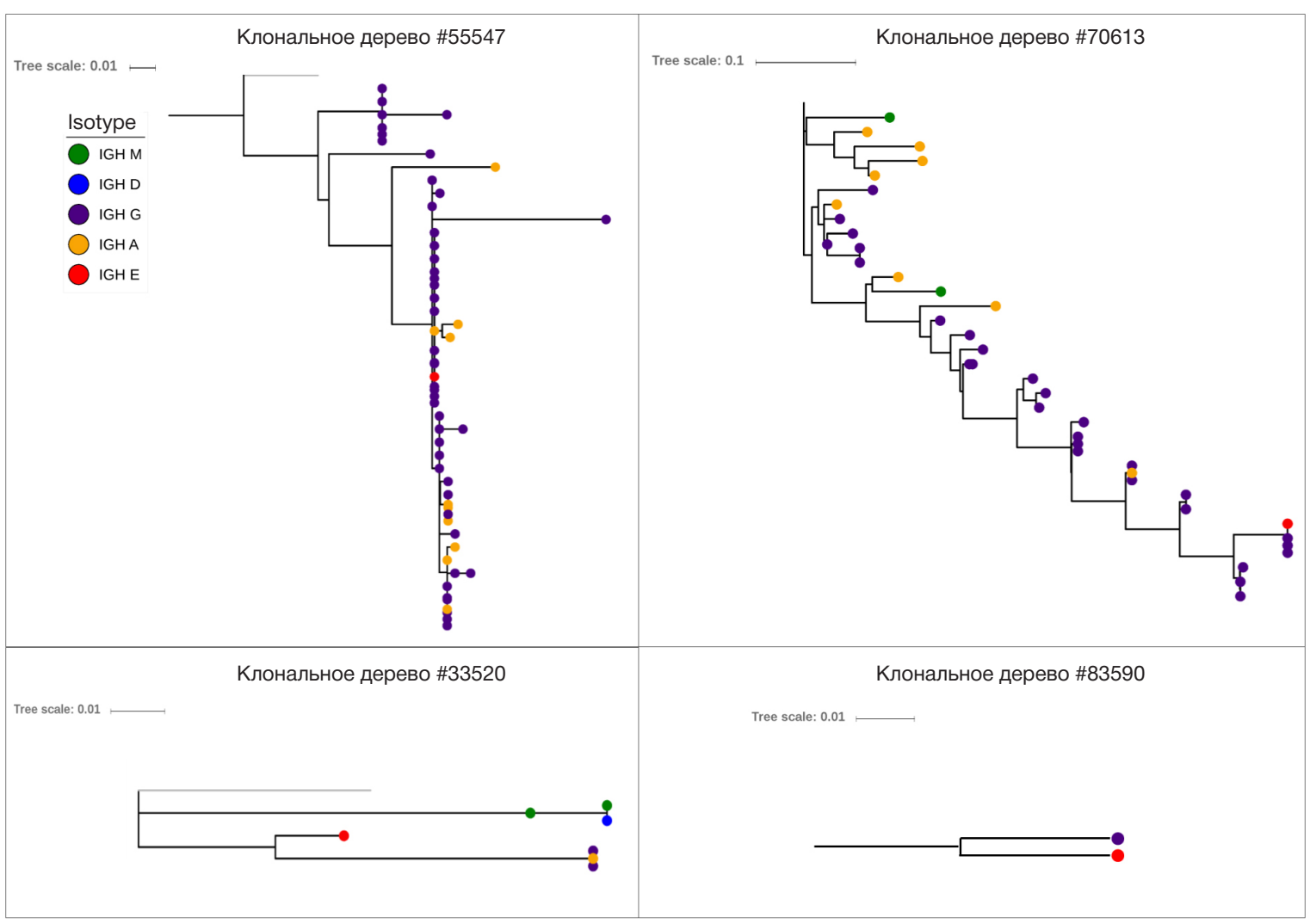

Рис. 6. Филогенетические деревья для IgЕ-содержащих клональных групп, содержащих клонотипы и других изотипов. Каждая точка представляет собой уникальный клонотип IGH. Цветом отмечены клонотипы разных изотипов (темно-синим — IgG, красным — IgE, оранжевым — IgA, зеленым — IgM, синим — IgD). Длина ветвей отражает расстояние между узлами по количеству мутаций между последовательностями. «тreе sсаle» - шкала, отражающая масштаб, в котором построено клональное древо

этом рост уровня сывороточного slgЕ к ольхе оказался в большей степени ассоциирован с ростом уровня пыльцы березы, но не ольхи, у всех доноров. Такой результат, по всей видимости, обусловлен кросс-реактивностью аллергенспецифичных IgE к пыльце березы в отношении антигенов пыльцы ольхи и может свидетельствовать об отсутствии специфичных антител к уникальным антигенам ольхи у доноров в нашем исследовании. Вместе с тем, так как уровень slgE к пыльце ольхи не был исследован до начала цветения ольхи - до начала измерений slgE прошло чуть более одной недели, в течение которой наблюдали низкий уровень (1-10 зерен на 1 м³) пыльцы ольхи в воздухе, нельзя исключить, что повышение уровня slgЕ к ольхе до максимального значения могло случиться в этот период (точки 1-3).

Момент начала роста концентрации slgE к пыльце березы и общего IgE совпадал с началом роста концентрации пыльцы березы у всех доноров, что может быть связано с увеличением количества IgEсекретирующих плазмобластов и плазматических клеток, диффференцирующихся из В-лимфоцитов памяти в ответ на стимуляцию аллергеном. Исследование динамики репертуара IGH и свойств последовательностей идентифицированных IGH-клонотипов в целом подтверждает это предположение. Полученные данные свидетельствуют о росте количества IgE-экспрессирующих плазмобластов и плазматических клеток в периферической крови после начала пыления березы, что отражает активный процесс дифференциации В-лимфоцитов. Высокий уровень гипермутаций, наблюдаемый в $\mathrm{lgE}$ клонотипах, указывает на длительную историю отбора рецепторов в ходе реакций в герминативных центрах, позволяя предполагать происхождение данных IgEсекретирующих клеток из В-лимфоцитов памяти.

В целом, полученные результаты указывают на то, что модель долгосрочного поддержания иммунологической памяти в контексте пищевой аллергии [6] может быть справедлива и в контексте сезонного аллергического ринита. В рамках данной модели долгоживущие lgЕ-секретирующие плазматические клетки имеют ограниченный период жизни ( 100 дней для мышиной модели), при этом IgG1-В-лимфоциты памяти служат долгосрочным «резервуаром", из которого пополняется пул lgE-секретирующих плазматических клеток. Процесс пополнения происходит в период контакта с аллергеном за счет быстрой пролиферации, изотип-свитчинга и дифференциации IgG1-B-лимфоцитов памяти под действием Th2-ассоциированных цитокинов (IL4, IL13 и др.). Результаты ранее опубликованного исследования репертуаров В-клеточных рецепторов в респираторной аллергии [18] не содержали сведений относительно принадлежности клонотипов к определенным субпопуляциям, но тем не менее свидетельствовали о наличии клональных связей между lgG- и lgE-клонотипами в репертуарах тяжелых цепей иммуноглобулинов в периферической крови, что также служит косвенным подтверждением корректности модели, предложенной R. Jiménez-Saiz. Проведенный в рамках данного исследования филогенетический анализ lgЕ-содержащих клональных групп демонстрирует вероятное происхождение lgЕ-секретирующих плазматических клеток из lgG+ В-лимфоцитов памяти у пациентов с аллергическим риноконъюнктивитом, однако в то же время строго не исключает возможности иного происхождения IgEпродуцентов. 
Полученные нами данные также не исключают возможности того, что увеличение уровня сывороточного IgE происходит за счет более интенсивного производства и секреции антител уже существующими IgEсекретирующими плазматическими клетками. Средний срок жизни lgE $^{+}$плазматических клеток в красном костном мозге для человека остается неизученным. При этом повышенная концентрация IgE в сыворотке больных аллергическим ринитом наблюдается и вне сезона цветения, позволяя предположить, что срок жизни соответствующих плазматических клеток может превышать время между двумя сезонами пыления. Однако, принимая во внимание ранее опубликованные данные о корреляции сывороточного уровня IgE и числа $\mathrm{IgE}^{+}$плазматических клеток в периферической крови [19], более вероятным объяснением роста сывороточного уровня общего и специфичного IgE представляется увеличение числа IgE-секретирующих клеток, что также согласуется с результатами настоящей работы.

\section{ВЫВОДЫ}

За счет существенно более высокого, по сравнению с опубликованными ранее исследованиями, временного разрешения при мониторинге уровня антител в сыворотке, удалось продемонстрировать, что момент начала роста концентрации общего и специфичного к пыльце березы lgЕ в контексте сезонной аллергии на березовую пыльцу совпадает с моментом начала роста концентрации пыльцы березы. При этом динамика роста уровней общего и специфичного IgE согласуется с количеством пыльцы березы в воздухе.

Результаты высокопроизводительного секвенирования и анализа репертуаров тяжелых цепей клеток В-лимфоцитарного ряда в сочетании с данными, полученными на мышиной модели пищевой аллергии другими авторами, позволяют предположить, что подобный прирост вероятнее всего вызван увеличением количества IgE-секретирующих плазматических клеток. Анализ нуклеотидных последовательностей IgE-содержащих клональных групп разных субпопуляций В-клеточного ряда показал высокое сходство последовательностей IgE- и IgG-клонотипов и присутствие в данных группах IgG-клонотипов, представляющих фракцию lgG $^{+}$ В-лимфоцитов памяти, что позволяет предположить происхождение lgE-секретирующих клеток из пула IgG+ лимфоцитов.

Малый размер выборки пациентов не позволяет заключить, что полученные характеристики отражают общие закономерности для всех пациентов в силу предполагаемого многообразия эндотипов аллергического риноконъюнктивита. Полученные в работе результаты свидетельствуют о сходстве механизма долгосрочного поддержания иммунной памяти при САР с таковым при пищевой аллергии. Для подтверждения данного предположения необходимо продолжить исследование на существенно более многочисленной группе пациентов с более детальной клинической характеристикой пациентов. Недостаточная изученность механизмов поддержания аллергенспецифичной реактивности иммунной системы определяет необходимость подобных исследований для разработки новых способов терапии, направленных на нарушение таких механизмов. Например, блокирование процесса переключения изотипа на $\mathrm{lg}$ при дифференцировке $\mathrm{IgG}$-аллергенспецифичных В-клеток памяти (например, за счет подавления эффекта цитокинов, производимых Th2-Т-клетками, при помощи моноклонального антитела к IL4R) может стать перспективной терапевтической стратегией. Сведения о динамике сывороточного уровня антител на фоне изменения концентрации аллергена в воздухе, полученные в настоящей работе, необходимы в дальнейшем при изучении сезонной динамики представленности lgE-секретирующих аллергенспецифичных клеток.

\section{Литература}

1. Bauchau V, Durham SR. Prevalence and rate of diagnosis of allergic rhinitis in Europe. European Respiratory Journal. 2004; 24 (5): 758-64. https://doi.org/10.1183/09031936.04.00013904.

2. Biedermann T, Winther L, Till SJ, Panzner P, Knulst A, Valovirta E. Birch pollen allergy in Europe. Allergy. 2019; 74 (7): all.13758. https://doi.org/10.1111/all.13758.

3. Penagos M, Eifan AO, Durham SR, Scadding GW. Duration of Allergen Immunotherapy for Long-Term Efficacy in Allergic Rhinoconjunctivitis. Current Treatment Options in Allergy. 2018; 5 (3): 275-90. https://doi.org/10.1007/s40521-018-0176-2.

4. Balbino B, Conde E, Marichal T, Starkl P, Reber LL. Approaches to target IgE antibodies in allergic diseases. Pharmacology \& Therapeutics. 2018; (191): 50-64. https://doi.org/10.1016/j. pharmthera.2018.05.015.

5. Rudulier CD, Tonti E, James E, Kwok WW, Larché M. Modulation of CRTh2 expression on allergen specific T cells following peptide immunotherapy. Allergy. 2019; all.13867. https://doi.org/10.1111/ all.13867.

6. Jiménez-Saiz R, Chu DK, Mandur TS, Walker TD, Gordon ME, Chaudhary $\mathrm{R}$, et al. Lifelong memory responses perpetuate humoral TH2 immunity and anaphylaxis in food allergy. Journal of Allergy and Clinical Immunology. 2017; 140 (6): 1604-15. https:// doi.org/10.1016/j.jaci.2017.01.018.

7. Jiménez-Saiz R, Bruton K, Koenig JF, Waserman S, Jordana M. The IgE memory reservoir in food allergy. The Journal of Allergy

and Clinical Immunology. 2018; 142 (5): 1441-3. https://doi. org/10.1016/j.jaci.2018.08.029.

8. Beeh K, Beier J, Buhl R. Seasonal variations of serum-IgE and potential impact on dose-calculation of omalizumab (rhuMab-E25, anti-lgE). Pneumologie. 2004; 58 (08): 546-51. https://doi. org/10.1055/s-2004-818483.

9. Sato K, Nakazawa T, Sahashi N, Kochibe N. Yearly and Seasonal Changes of Specific IgE to Japanese Cedar Pollen in a Young Population. Annals of Allergy, Asthma \& Immunology. 1997; 79 (1): 57-61. https://doi.org/10.1016/S1081-1206(10)63085-2.

10. Gleich GJ, Jacob GL, Yunginger JW, Henderson LL. Measurement of the absolute levels of IgE antibodies in patients with ragweed hay fever. Journal of Allergy and Clinical Immunology. 1977; 60 (3): 188-98. https://doi.org/10.1016/0091-6749(77)90123-3.

11. Turchaninova MA, Davydov A, Britanova OV, Shugay M, Bikos V, Egorov ES, et al. High-quality full-length immunoglobulin profiling with unique molecular barcoding. Nature Protocols. 2016; 11 (9): 1599-616. https://doi.org/10.1038/nprot.2016.093.

12. Shugay M, Britanova OV, Merzlyak EM, Turchaninova MA, Mamedov IZ, Tuganbaev TR, et al. Towards error-free profiling of immune repertoires. Nature Methods. 2014; (11): 653. http:// dx.doi.org/10.1038/nmeth.2960.

13. Bolotin DA, Poslavsky S, Mitrophanov I, Shugay M, Mamedov IZ, Putintseva EV, et al. MiXCR: software for comprehensive adaptive immunity profiling. Nature Methods. 2015; (12): 380. https://doi. 
org/10.1038/nmeth.3364.

14. R Core Team. R: A language and environment for statistical computing. R Foundation for Statistical Computing. Vienna, Austria. 2013. URL http://www.R-project.org/.

15. Wickham H. ggplot2: Elegant Graphics for Data Analysis. New York: Springer-Verlag, 2016. Retrieved from https://ggplot2. tidyverse.org.

16. Gupta NT, Vander Heiden JA, Uduman M, Gadala-Maria D, Yaar G, Kleinstein SH. Change-O: a toolkit for analyzing large-scale B cell immunoglobulin repertoire sequencing data. Bioinformatics. 2015; 31 (20): 3356-8. DOI: 10.1093/bioinformatics/btv359.

17. Sudhir Kumar, Glen Stecher, Koichiro Tamura. MEGA7: Molecular

\section{References}

1. Bauchau V, Durham SR. Prevalence and rate of diagnosis of allergic rhinitis in Europe. European Respiratory Journal. 2004; 24 (5): 758-64. https://doi.org/10.1183/09031936.04.00013904.

2. Biedermann T, Winther L, Till SJ, Panzner P, Knulst A, Valovirta E. Birch pollen allergy in Europe. Allergy. 2019; 74 (7): all.13758. https://doi.org/10.1111/all.13758.

3. Penagos M, Eifan AO, Durham SR, Scadding GW. Duration of Allergen Immunotherapy for Long-Term Efficacy in Allergic Rhinoconjunctivitis. Current Treatment Options in Allergy. 2018; 5 (3): 275-90. https://doi.org/10.1007/s40521-018-0176-2.

4. Balbino B, Conde E, Marichal T, StarkI P, Reber LL. Approaches to target IgE antibodies in allergic diseases. Pharmacology \& Therapeutics. 2018; (191): 50-64. https://doi.org/10.1016/j. pharmthera.2018.05.015.

5. Rudulier CD, Tonti E, James E, Kwok WW, Larché M. Modulation of CRTh2 expression on allergen specific $T$ cells following peptide immunotherapy. Allergy. 2019; all.13867. https://doi.org/10.1111/ all.13867.

6. Jiménez-Saiz R, Chu DK, Mandur TS, Walker TD, Gordon ME, Chaudhary $R$, et al. Lifelong memory responses perpetuate humoral TH2 immunity and anaphylaxis in food allergy. Journal of Allergy and Clinical Immunology. 2017; 140 (6): 1604-15. https:// doi.org/10.1016/j.jaci.2017.01.018.

7. Jiménez-Saiz R, Bruton K, Koenig JF, Waserman S, Jordana M. The IgE memory reservoir in food allergy. The Journal of Allergy and Clinical Immunology. 2018; 142 (5): 1441-3. https://doi. org/10.1016/j.jaci.2018.08.029.

8. Beeh K, Beier J, Buhl R. Seasonal variations of serum-IgE and potential impact on dose-calculation of omalizumab (rhuMab-E25, anti-lgE). Pneumologie. 2004; 58 (08): 546-51. https://doi. org/10.1055/s-2004-818483.

9. Sato K, Nakazawa T, Sahashi N, Kochibe N. Yearly and Seasonal Changes of Specific IgE to Japanese Cedar Pollen in a Young Population. Annals of Allergy, Asthma \& Immunology. 1997; 79 (1): 57-61. https://doi.org/10.1016/S1081-1206(10)63085-2.

10. Gleich GJ, Jacob GL, Yunginger JW, Henderson LL. Measurement of the absolute levels of IgE antibodies in patients with ragweed
Evolutionary Genetics Analysis Version 7.0 for Bigger Datasets, Molecular Biology and Evolution. 2016; 33 (7): 1870-4. https:// doi.org/10.1093/molbev/msw054.

18. Looney TJ, Lee JY, Roskin KM, Hoh RA, King J, Glanville J, et al. Human B-cell isotype switching origins of IgE. Journal of Allergy and Clinical Immunology. 2016; 137 (2): 579-86. https://doi. org/10.1016/j.jaci.2015.07.014.

19. Horst A, Hunzelmann N, Arce S, Herber M, Manz RA, Radbruch A, et al. Detection and characterization of plasma cells in peripheral blood: Correlation of $\mathrm{IgE}^{+}$plasma cell frequency with IgE serum titre. Clinical and Experimental Immunology. 2002; 130 (3): 370-8. https://doi.org/10.1046/j.1365-2249.2002.02025.x.

hay fever. Journal of Allergy and Clinical Immunology. 1977; 60 (3): 188-98. https://doi.org/10.1016/0091-6749(77)90123-3.

11. Turchaninova MA, Davydov A, Britanova OV, Shugay M, Bikos V, Egorov ES, et al. High-quality full-length immunoglobulin profiling with unique molecular barcoding. Nature Protocols. 2016; 11 (9): 1599-616. https://doi.org/10.1038/nprot.2016.093.

12. Shugay M, Britanova OV, Merzlyak EM, Turchaninova MA, Mamedov IZ, Tuganbaev TR, et al. Towards error-free profiling of immune repertoires. Nature Methods. 2014; (11): 653. http:// dx.doi.org/10.1038/nmeth.2960.

13. Bolotin DA, Poslavsky S, Mitrophanov I, Shugay M, Mamedov IZ, Putintseva EV, et al. MiXCR: software for comprehensive adaptive immunity profiling. Nature Methods. 2015; (12): 380. https://doi. org/10.1038/nmeth.3364.

14. R Core Team. R: A language and environment for statistical computing. R Foundation for Statistical Computing. Vienna, Austria. 2013. URL http://www.R-project.org/.

15. Wickham H. ggplot2: Elegant Graphics for Data Analysis. New York: Springer-Verlag, 2016. Retrieved from https://ggplot2. tidyverse.org.

16. Gupta NT, Vander Heiden JA, Uduman M, Gadala-Maria D, Yaar G, Kleinstein SH. Change-O: a toolkit for analyzing large-scale B cell immunoglobulin repertoire sequencing data. Bioinformatics. 2015; 31 (20): 3356-8. DOI: 10.1093/bioinformatics/btv359.

17. Sudhir Kumar, Glen Stecher, Koichiro Tamura. MEGA7: Molecular Evolutionary Genetics Analysis Version 7.0 for Bigger Datasets, Molecular Biology and Evolution. 2016; 33 (7): 1870-4. https:// doi.org/10.1093/molbev/msw054.

18. Looney TJ, Lee JY, Roskin KM, Hoh RA, King J, Glanville J, et al. Human B-cell isotype switching origins of lgE. Journal of Allergy and Clinical Immunology. 2016; 137 (2): 579-86. https://doi. org/10.1016/j.jaci.2015.07.014.

19. Horst A, Hunzelmann N, Arce S, Herber M, Manz RA, Radbruch A, et al. Detection and characterization of plasma cells in peripheral blood: Correlation of $\mathrm{lg} \mathrm{E}^{+}$plasma cell frequency with lgE serum titre. Clinical and Experimental Immunology. 2002; 130 (3): 370-8. https://doi.org/10.1046/j.1365-2249.2002.02025.x. 